\title{
A Two-step Sequential Extraction for Analyzing Hardly Accessible Precious Metals in Sulfide Ore-bearing Sedimentary Rocks
}

\author{
Medet Junussov, Ferenc Mádai and Ferenc Kristály \\ Faculty of Earth Sciences and Engineering, Miskolc University, H-3515 Miskolc-Egyetemváros, Hungary
}

\begin{abstract}
The work concentrates on extraction of precious metals (Au, Ag, Pd, Pt) and As, $\mathrm{Sb}, \mathrm{Cu}, \mathrm{Pb}, \mathrm{Zn}$, and Fe which are bound to sulfide-ore minerals in sedimentary rocks, using a two-step sequential extraction experiment with two chemical reagents (hydrogen peroxide and aqua regia) on three rock specimens from the black shale formation in Bakyrchik gold-sulfide deposit in North-East Kazakhstan. The experiment allows to determine the speciation of hardly accessible precious metals and to identify the most productive ore-forming stage from the three identified ones. Analytical methods are used for determining polysulfide mineral textures (optical microscopy), mineralogical (XRPD) and chemical compositions (XRF), and for measuring extracted metals concentrations (ICP-OES) in experimental procedures. The analytical results show that the first stage is more productive in gold (total extraction $2.8 \mathrm{ppm}$ ) than others and the second stage is more productive in $\mathrm{Ag}$ (total $1.6 \mathrm{ppm}$ ) and $\mathrm{Pd}$ (total $0.01 \mathrm{ppm}$ ), while the last stage is more productive in Pt (0.019 ppm) in the deposit.
\end{abstract}

Key words: Sulfide minerals, precious metals, hydrogen peroxide, aqua regia.

\section{Introduction}

The scope of this paper is to determine elemental concentrations of precious metal species Au, Ag, Pd, Pt in sulfide ore-bearing sedimentary rocks of Bakyrchik gold deposit. The Bakyrchik gold deposit has hardly accessible precious metals, because they appear in colloidal size [1] and as inclusions in crystals of disseminated arsenic-containing sulfide minerals in terrigenous sedimentary rocks [2]. The sulfide ore-bearing sedimentary rocks of the mineral deposit occur in three different ore generation stages. The three stages of ore formations have various concentrations of precious metals which are frequently related to arsenic-bearing sulfide minerals [3]. Therefore, they are research objects for detecting the more productive stage in precious metallic concentrations in the Bakyrchik deposit.

Corresponding author: Medet Junussov, Ph.D. student, research field: geology of Au-U mineral resources of black shale formation.

\section{Materials and Methods}

\subsection{The Deposit and Its Ore Mineralization}

The ore-bearing sedimentary rocks of the deposit are situated in a Bukon suite of Middle Carboniferous [4] with $280 \mathrm{t}$ (since 2014 of ore estimation) of gold reserve with average grade of $7.7 \mathrm{~g} / \mathrm{t}$ [5]. The ore occurs in lensoidal forms of 120-250 m in width and $500-700 \mathrm{~m}$ in length [6]. The ore formation is a syngeneic-sedimentogenic gold-bearing material in the Qyzyl shear zone, it belongs to a gold-sulfide type of mineralized zone [4]. The gold mineralization is localized in thin-rhythmically laminated marl, siltstones, felsic tuffs and sandstone. The siltstone of them has the highest amount of gold-bearing arsenopyrite and pyrite [7]. The arsenopyrite content is $0.3-1.5 \%$ in the ore [4], the gold grades in arsenopyrite can reach more than $150 \mathrm{ppm}$, while $60 \mathrm{ppm}$ in arsenical pyrite [7]. The gold has ultra-fine microscopic forms of appearance such as ionic and colloidal [8]. Platinum group metals are also 
distributed in the arsenic pyrite and arsenopyrite-bearing ores up to $1 \mathrm{ppm}$ [8], forming in nano- and microforms [9]. The precious metals-bearing arsenic pyrite and arsenopyrite minerals of the Bakyrchik deposit occur in various paragenessis and show different morphology (see Fig. 1). Morphogenetic forms of arsenic pyrite and arsenopyrite crystals have differences in shape, size and chemical concentrations. The arsenic pyrite concentrates in chemogenic-terrigenous sediments of argillaceous and marl compositions [8]. There are three morphogenetic variations of pyrites such as (1) sedimentary-digenetic globular (no gold-containing); (2) cubic form (gold-containing) recrystallized from globular pyrite in circumstances of high pressure and temperature; and (3) pentagon dodecahedral pyrite (high gold-containing) which associates with arsenopyrite. The pyrites include different arsenic concentrations up to $3.94 \%$ in cubic pyrite and $4.86 \%$ in hexahedral pyrite [2]. While the arsenopyrite has two morphologic varieties such as acicular-prismatic (associating with invisible gold), which forms at the early productive stage of ore deposition, and tabular arsenopyrite associated with free gold [1]. The arsenopyrite was formed under the condition of metagenesis and dynamo-metamorphism [1]. The tabular arsenopyrite has more concentrations of gold than acicular-prismatic arsenopyrite [2]. The arsenopyrite in acicular-prismatic form is mostly of low temperature origin [10].

The gold of the deposit is a mantle source and came with ultramafic rocks of the oceanic base, which was transported and deposited on the following three geological processes [11]:

(1) In sedimentary-diagenetic process, the gold was transported by a bisulfide gold solution (sea water) through tectonic activation and depositing in the shallow zone and framboidal (globular) pyrite formed as well.

(2) In tectonic-metasomatic process, the gold was transported in a mineralizing solution as chloric gold complex (hydrothermal-metamorphic water) and depositing the gold in carbonaceous-terrigenous sediments and framboidal pyrites recrystallized to gold-containing cubic pyrite and high gold-containing pentagon-dodecahedral forms with arsenic element inclusions.

(3) In intrusive-thermal-metasomatic process, syngenetic and hydrothermal-metamorphogenic gold remobilized along the Qyzyl shear zone in the areas of intrusions, and then the gold reached final precipitations, originating ore generations stages.

In general, there are four stages of ore generation detected at the well-studied Bakyrchik deposit, but among the four stages were selected to analyze only three stages as precious metals-bearing ore formation for this work, they are:

(1) Early ore stage connected with quartz, sericite and gold-bearing arsenopyrite and pyrite (first productive stage) [12]. The stage occurs at $340-460{ }^{\circ} \mathrm{C}$ with 110-130 MPa forming gas-liquid composition without carbon dioxide (corresponding condition for much more productive of ore part) [3].

(2) Polymetallic ore stage, during which pyrite, sphalerite, chalcopyrite, galena, grey copper ore, and native gold were accumulated (second productive stage) [12]. This stage has homogenization of three phases with carbon dioxide at $160-360{ }^{\circ} \mathrm{C}$ [3].

(3) Quartz-antimonite stage with quartz, marcasite, jamesonite, enargite, and native $\mathrm{Sb}$ and $\mathrm{Au}$ (post ore stage) [12]. The stage occurs from gas-liquid solution at $160-200{ }^{\circ} \mathrm{C}$ [3].

Among the ore minerals, dominant ones are pyrite and arsenopyrite (from early ore stage) while marcasite, chalcopyrite, pyrrhotite and galena (polymetallic ore stage) are rarer [4] and the both stages were detected in the deep horizons [7]; while a quartz-stibnite association (post-ore stage) with native antimony, silver, and mercury is found in the near-surface horizons [7]. The polymetallic stage of ore generation is always accompanied spatiality with pyrite and arsenopyrite from the early-ore stage [3]. High $\mathrm{Au}$ 
concentration is correlated positively with As-rich compositions in sulfide minerals [3]. The antimony content increases toward the near-surface areas of orebodies, but Sb and Au contents show no correlation in Sb mineralization of gold-sulfide ores [11].

\subsection{Rock Samples and Analytical Uses}

Three samples have been selected for analytical observation and experiment from three ore generations stages in order to determine precious metallic speciation. The first sample belongs to early ore stage, the second is to polymetallic ore stage and third one is to the quartz-antimonite ore stage. They are shown in Fig. 1. Analytical works were carried out on all three samples with different methods. Namely, reflected light microscopy for determination of mineralogical composition, textures and presence of native gold grains; X-ray fluorescence for chemical composition; X-ray powder diffraction for mineralogical composition after and before leaching the samples by the sequential extraction experiment, and ICP-OES for measurement of elemental concentrations from soluble extractions after the experiment.

\subsection{Sample Preparation and Experiment Procedure}

The three rock samples were crushed down to less than $5 \mu \mathrm{m}$, having an agate mortar and pestle, and reducing samples size of powders with using method of coning and quartering. After crushing process, powder samples were weighed in total $10 \mathrm{~g}$ for the
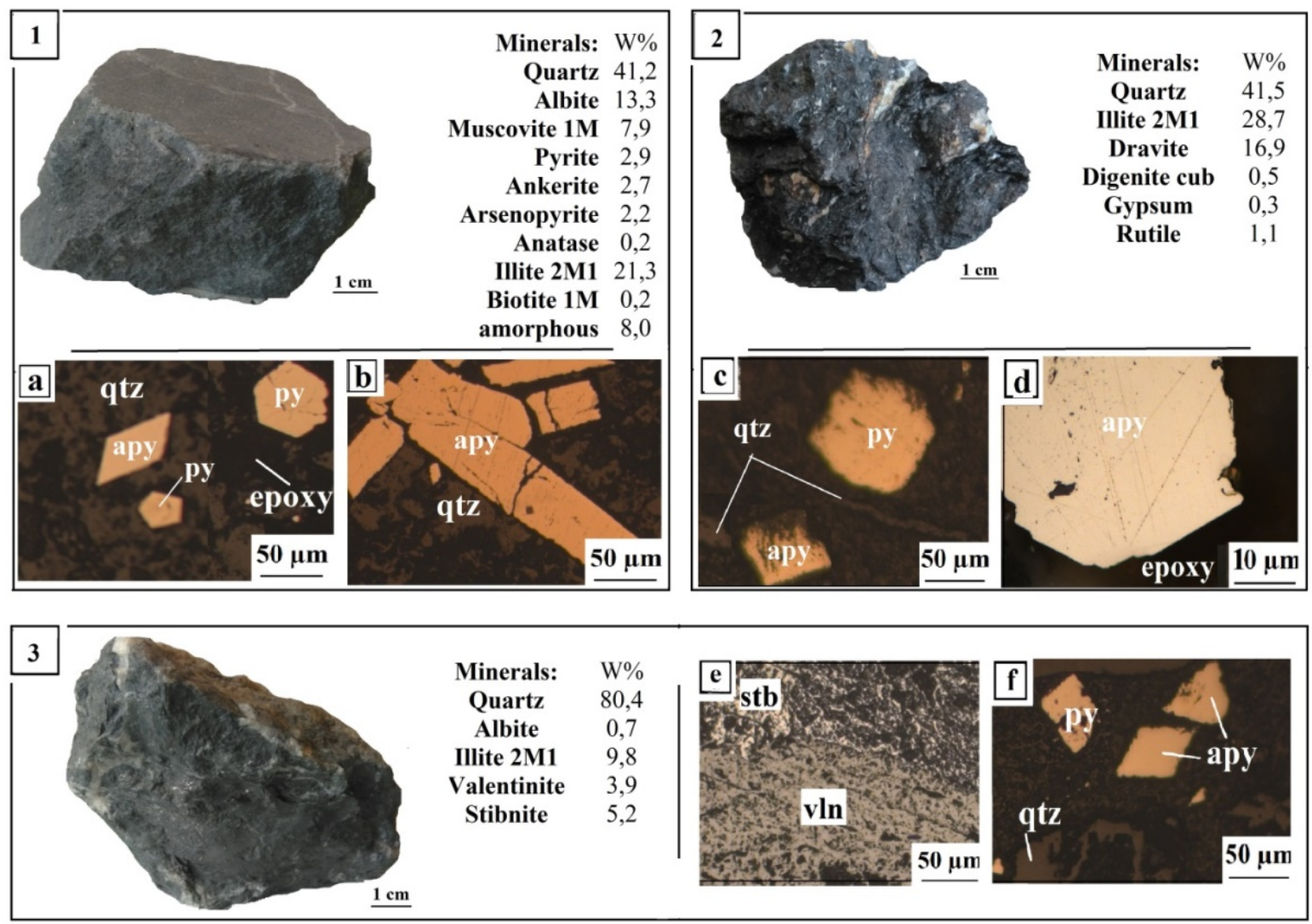

Fig. 1 Reflected light microscopy and mineralogical compositions of rock samples based on XRPD (BRUKER D8 ADVANCE $\mathrm{Cu}-\mathrm{K \alpha} 40 \mathrm{kV}, 40 \mathrm{~mA}$ ): 1. Sericizited carbonaceous-siltstone rock (early ore stage), a-tabular apy associated with pentahedral and hexahedral py, b-acicular-prismatic apy; 2. Carbonaceous siltstone rock with polymetals (polymetallic ore stage), c-tabular apy and hexahedral py, d-tabular-twin apy; 3 Sulfide-rich carbonaceous siltstone with quartz-antimonite veins (quartz-antimonite ore stage), e-stibnite valentinite, f-tabular apy with cubic py. Abbreviation: apy-arsenopyrite, py-pyrite, stb-stibnite, vln-valentinite, qtz-quartz. 
experiment. The experiment was performed based on previous experiments [14-16], taking two steps and two special acids. The first step moves components bound to organics and sulfides: for dissolving them, $18 \mathrm{~mL}$ of $30-35 \% \mathrm{H}_{2} \mathrm{O}_{2}$ is used with adding into glass beaker $(100 \mathrm{~mL})$ to $2 \mathrm{~g}$ of powder sample and then manually mixed together. After the mixing process the glass test tube was placed in a water bath at $85{ }^{\circ} \mathrm{C}$ water for 1 hour. After this procedure it was decanted and the residue was dried at $60{ }^{\circ} \mathrm{C}$. The second stage is residual digestion, which leaches non-dissolving parts of sulfide-bearing fractions in dried powder material from the previous step. $1 \mathrm{~g}$ of the dried powder material was mixed with $9 \mathrm{~mL}$ aqua regia $(68 \%$ $\left.\mathrm{HNO}_{3}-37 \% \mathrm{HCl}(1: 3)\right)$. Then, it was placed to water bath at $100{ }^{\circ} \mathrm{C}$ water at 1 hour. After finishing, the extract was filtered as the former process. The final residue contained silicate materials of the sample which was not dissolved by reagents.

\section{Results and Discussion}

According to results of the sequential extraction experiment (Table 2) and X-Ray diffraction analysis (Fig. 2) one may affirm that in the first step, the hydrogen peroxide had no completely digestive effects on all sulfide-ore minerals, especially arsenic-bearing sulfides, which were dissolved partly, following base-metal sulfide and antimony-sulfide minerals.

The during digestion process in the first step, the arsenic-bearing sulfide minerals of the three powder samples released some precious metals such as maximum grade $0.7 \mathrm{ppm}$ of $\mathrm{Au}$ and $\mathrm{Ag} 0.3 \mathrm{ppm}$ from sample 1; Au 0.2 ppm, Pd 0.01 and Pt 0.005 ppm from sample 2 and Au 0.4 ppm from sample 3. However, in the second step, aqua regia influenced completely on all sulfide-ore bearing powder samples, excluding silicate minerals. By the acid precious metallic species were released with more concentrations into residue of arsenic-bearing sulfide materials than from the first step. The highest grade of Au 2.1 ppm, and 0.4 ppm of Ag from sample 1; Ag $1.6 \mathrm{ppm}$ from sample 2; and 0.4 ppm of Au, 0.2 ppm of Ag and 0.019 ppm of Pt from sample 3 (Fig. 2) were received. It was detected that no-dissolving silicate minerals (quartz, mica, feldspar and illite almost in all samples) and titanium oxide (rutile in the sample 2, indicating quantities of XRF in Table 1) were not dissolved by acids in the two steps of the experiment, but all sulfide-ore minerals were dissolved completely in the second step, due to the aqua regia acid (shown in Fig. 2). The extracted gold is

Table 1 Chemical compositions of three samples based on WDX-XRF (RIGAKU Supermini Pd source, 50 kV-4 mA).

\begin{tabular}{|c|c|c|c|c|c|c|c|}
\hline \multirow{2}{*}{$\begin{array}{l}\text { Chemical } \\
\text { elements }\end{array}$} & Sample 1 & Sample 2 & Sample 3 & \multirow{2}{*}{$\begin{array}{l}\text { Chemical } \\
\text { elements }\end{array}$} & Sample 1 & Sample 2 & Sample 3 \\
\hline & & unit $\%$ & & & \multicolumn{3}{|c|}{ unit ppm } \\
\hline $\mathrm{SiO}_{2}$ & 60.7 & 58.4 & 74 & As & 13,000 & 2,700 & 1,800 \\
\hline $\mathrm{Al}_{2} \mathrm{O}_{3}$ & 19.3 & 17.7 & 6 & $\mathrm{Cu}$ & 51 & 55 & 23 \\
\hline $\mathrm{MgO}$ & 0.95 & 1.38 & 0.2 & $\mathrm{Zn}$ & 218 & 104 & 10 \\
\hline $\mathrm{Fe}_{2} \mathrm{O}_{3}$ & 4.87 & 5.96 & 0.25 & $\mathrm{~Pb}$ & 27 & 17 & 35 \\
\hline $\mathrm{MnO}$ & 0.036 & 0.061 & $<0.005$ & $\mathrm{Sb}$ & 88 & 102 & 137,000 \\
\hline $\mathrm{TiO}_{2}$ & 0.690 & 0.893 & 0.116 & $\mathrm{~S}$ & 28,000 & 9,000 & 39,000 \\
\hline
\end{tabular}

Table 2 Results of extracted precious metal concentrations based on ICP-OES (720 ES made by VARIAN Inc., Arial Plasma-view, simultaneous multi-element ICP spectrometer).

\begin{tabular}{lllllll}
\hline \multicolumn{2}{l}{ Precious metal concentrations from two steps of the experiment } \\
\hline \multirow{2}{*}{ Chemical elements } & \multicolumn{7}{l}{ Step I / unit ppm } & \multicolumn{2}{l}{ Step II / unit ppm } \\
\cline { 2 - 7 } & Sample 1 & Sample 2 & Sample 3 & Sample 1 & Sample 2 & Sample 3 \\
\hline $\mathrm{Au}$ & 0.7 & 0.2 & 0.4 & 2.1 & 0.1 & 0.4 \\
$\mathrm{Ag}$ & 0.3 & - & - & 0.4 & 1.6 & 0.2 \\
$\mathrm{Pd}$ & - & 0.01 & - & - & - & - \\
$\mathrm{Pt}$ & - & 0.005 & - & - & - & 0.019 \\
\hline
\end{tabular}



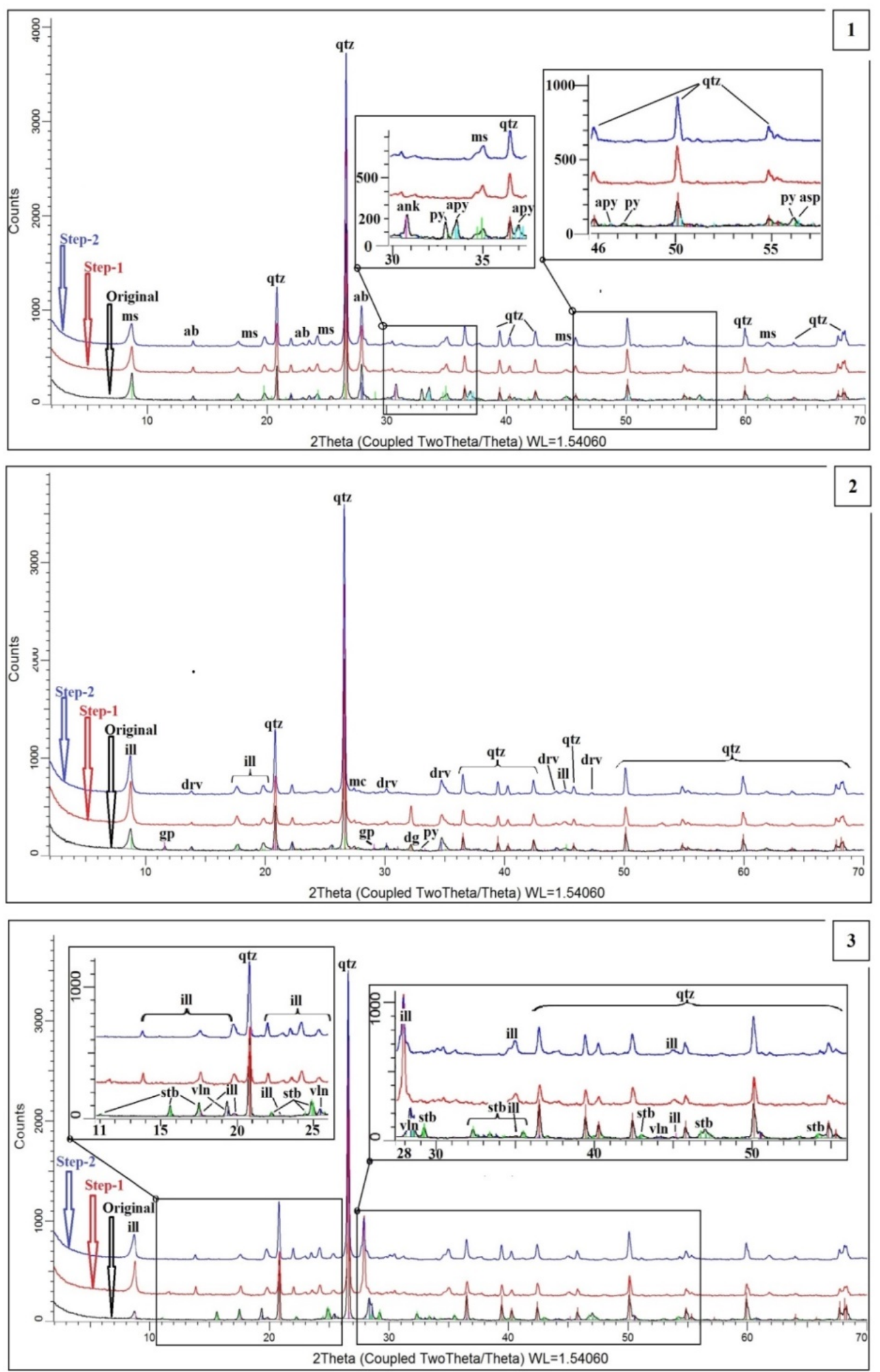

Fig. 2 Quantitative XRD analyses of three samples (numbers of graphs are similar with sample labels) after two-step digestions and comparing with original mineral composition. (qtz-quartz; ab-albite; ms-muscovite; mc-microcline; ank-ankerite; py-pyrite; apy-arsenopyrite; gy-gypsum; ill-illite; stb-stibnite; vln-valentinite; drv-dravite; dg-digenite). 
Table 3 Extracted precious metals in the three ore generation stages (total calculation in ppm from two steps of the experiment).

\begin{tabular}{llll}
\hline \multirow{2}{*}{ Precious metals } & \multicolumn{2}{c}{ Three ore formation stages / their concentrations } \\
\cline { 2 - 4 } & $\mathrm{I}$ & $\mathrm{II}$ & $\mathrm{III}$ \\
\hline $\mathrm{Au}$ & 2,8 & 0.3 & 0.8 \\
$\mathrm{Ag}$ & 0,7 & 1.6 & 0.2 \\
$\mathrm{Pd}$ & - & 0.01 & - \\
$\mathrm{Pt}$ & - & 0.005 & 0.019 \\
TOTAL & 3.5 & 1.9 & 1 \\
\hline
\end{tabular}

in colloidal size, because its presence and other precious materials as well were not detected under optical microscopy. They were released from crystalline structure of arsenic-bearing sulfide minerals. The productive phases of precious metals (calculated from two-step extraction) are the sulphides of the early ore-forming stage (sample 1) with $3.5 \mathrm{ppm}(\mathrm{Au}+\mathrm{Ag}$ ), while the polymetallic stage (sample 2) has $1.9 \mathrm{ppm}$ $(\mathrm{Ag}+\mathrm{Pd}+\mathrm{Pt})$ and the quartz-antimony stage (sample 3$)$ with $1 \mathrm{ppm}(\mathrm{Au}+\mathrm{Ag})$ is weakly productive (listed in Table 3).

The results of analytical and experimental works show that the three samples have different potential values of precious metals within different contents of arsenic-bearing sulfide minerals, relatively. The concentrations of precious metals are changed by quantity of arsenic pyrite and arsenopyrite minerals in the samples. Thus, the precious metals highly concentrated (up to $3.5 \mathrm{ppm}$ ) with increasing content of arsenic-bearing sulfide minerals (up to $5.1 \mathrm{ppm}$ ) in the samples, especially it is notable in the sample 1, which is related to the early ore formation stage (listed in Table 3).

The results of the prior scientific materials indicate that more concentrations of precious metals among arsenic-bearing sulfide minerals are hexahedral arsenic pyrite and tabular arsenopyrite. Hence, microscopic observations among textures of arsenic pyrite and arsenopyrite minerals were detected that hexahedral form in arsenic pyrite and tabular form in arsenopyrite spread more than another forms in the samples and they increase in the sample 1 (early ore stage), then they decrease gradually from the sample 2, continuing (polymetallic ore stage ) to the sample 3 (quartz-antimony stage). It is the good evidence that precious metals concentrations decrease dramatically with lower content of arsenic-bearing sulfide minerals from early ore stage up to quartz-antimony generations stage. Because, the during tectonic- and intrusive-metasomatic processes of ore formations containing the gold and arsenic associations were “transition" elements together with Ag-Pd-Pt in the minerals of arsenic pyrite and arsenopyrite. They were accompanied spatially with accumulating and increasing on the early ore stage, then gradually decreasing to the end from polymetallic ore stage to last stage in the deposit.

\section{Conclusions}

The sequential extraction is a suitable method for extracting and detecting hardly-accessible precious metals in a colloidal size from arsenic-bearing sulfide minerals. By the sequential extraction combined with XRPD using the two chemical reagents in boiling water-bath condition were differently digestible effects. The hydrogen peroxide was not relevant chemical reagent to dissolve totally polysulfide-ore minerals. Whereas, the aqua regia dissolved easily polysulfide-ore minerals such as arsenic-, base metaland antimony-bearing sulfide minerals in the samples. All the three ore generations of the Bakyrchik deposit are precious metals-containing stages, especially, early ore generation stage (sample 1) is much more productive in $\mathrm{Au}$; Ag compared to the polymetallic ore stage (sample 2) and post-ore stage has Pt (sample 3). Thereby, the method with suitable acid has 
relatively prospecting approaches to facilitate exploration of hardly-accessible precious metals in the deposit.

\section{Acknowledgments}

I thank Z. T. Umarbekova for the opportunity of sharing with sample collections. Also, my special thanks go to Dr. F. Madai for consultation and patience; and. Dr. F. Kristály (X-Ray diffraction), F. Moricz (X-Ray Flouresence) and Dr. B. Oliver (ICP-OES) for their helps with analytical works.

The work was supported by the Miskolc University (project EFOP-3.6.1-16-2016-00011).

\section{References}

[1] Kovalev, K. R., Kalinin, Yu. A., Naumov, E. A., Kolesnikova, M. K., and Korolyuk, V. N. 2011. "Gold-bearing Arsenopyrite in Eastern Kazakhstan Gold-Sulfide Deposits.” J. Russian Geol. and Geoph. 52: 178-14. Accessed January 20, 2011. https://doi.org/10.1016/j.rgg.2010.12.014.

[2] Medet, J. 2018. "Looking for 'Invisible Gold' and Its Concentrations in Arsenic-containing Sulfide Minerals of Bakyrchik Gold Deposit.” In Proceedings of the XXXII MicroCAD International Multidisciplinary Scientific Conference, 8.

[3] Novojilov, Yu. I., and Gavrilov, A. M. 1999. Gold-Sulfide Deposits in Carbonaceous-Terrigenous Formations. Moscow: CNIGRI.

[4] Umarbekova, Z. T., Dyusembayeva, K. S., and Kubashev, K. T. 2017. "The Bakyrchik Deposit and Views on the Formation of the Mineral Deposits in Black Shale Beds.” In Proceedings of the 17th International Multidisciplinary Scientific Geoconference SGEM 2017, 1111-7.

[5] Forbes Kazakhstan. 2017. "Why Polymetal Took on the Most 'Stubborn' Field of Kazakhstan.” Forbes
Kazakhstan News. Accessed December 25, 2018. https://forbes.kz/process/resources/pochemu_polymetal_v zyalsya_za_samoe_upornoe_mestorojdenie_rk/.

[6] Plekhova, K. R., Zhautekov, T. M., and Bagybek, L. D. 2014. “The Morphogenetic Diversity of the Pyrite as Mineralogical Search Criteria for Gold-Bearing Rocks of the West Kalba metallogenic Zone.” Almaty: Header of the Academyof Sciences 1 (1): 45-53.

[7] Levitan, G. 2008. Gold Deposits of the CIS. USA: Xlibris Corporation.

[8] Rafaylovich, S., Myzernaya, M. A., and D’yachkov, B. A. 2011. Giant Black Shale Hosted Gold Deposits: Formation and Similarity. Almaty: EKGTU named Serikbaeva D.

[9] Narseev, V. A., Gostev, Yu. V., Zaharov, A. V., et al. 2001. Bakyrchik (Geology, Geochemistry, Ore Generation). Moscow: CNIIGRI.

[10] Seitkan, A., Simon, A., and Redfern, T. 2016. "Processing Double Refractory Gold-Arsenic-Bearing Concentrates by Direct Reductive Melting.” J. Miner. Engine. 98: 286-16. Accessed September 13, 2016. https://doi.org/10.1016/j.mineng.2016.08.017.

[11] Kulp, T. R., and Pratt, L. M. 2004. "Speciation and Weathering of Selenium in Upper Cretaceous Chalk and Shale from South Dakota and Wyoming, USA.” Geochim et Cosmochim Acta 68: 3687-701.

[12] Kovalev, K. R., Kalinin, Yu. A., Naumov, E. A., and Myagkaya, M. K. 2014. "Relationship of Antimony with Gold Mineralization in the Ore Districts of Eastern Kazakhstan.” J. Russian Geol. and Geophy. 55: 1170-12. Accessed September 2104. https://doi.org/10.1016/j.rgg.2014.09.003.

[13] HE, L., ZEN, R., and LIN, L. 1993. Geology of Guizhou Gold Deposits. Guiyan: Geological Publishing House.

[14] Dold, B., and Fontboté, L. 2001. "Element Cycling and Secondary Mineralogy in Porphyry Copper Tailings as a Function of Climate, Primary Mineralogy and Mineral Processing.” Geochemistry Exploration 74 (1-3): 3-55.

[15] Anbar, A. D., and Rouxel, O. 2007. "Metal Stable Isotopes in Paleoceanography.” Annu Rev Earth Planet Sci 35: 717-46. 